\title{
CLINICAL ETHICS
}

\section{Ethical considerations for services offering one-to-one guidance for primary care practitioners interested in research}

\section{H Bateman}

J Med Ethics 2002;28:33-36

Correspondence to:

H Bateman;

hb208@medschl.cam.ac.uk

Revised version received 19 April 2001

Accepted for publication 30 April 2001
Initiatives which offer support to primary care practitioners interested in research have become widespread in the UK. There has been little debate, however, about the ethical issues involved in such interactions with practitioners. Established codes of practice and analyses of the institutional and strategic contexts have been used to inform this discussion. The paper concludes with a recommendation that more explicit quasi-contractual relationships should be negotiated between those offering and those seeking help. in nitiatives which offer help to primary care practitioners interested in research have become widely established in the

UK. ${ }^{1}$ Their objectives are informed by the work of various national policy reports. ${ }^{2-4}$ The approaches through which these objectives are realised have been left largely to the discretion of the individual initiatives. The NHS report, ${ }^{2}$ the Evans report, ${ }^{1}$ and papers from initiatives with a remit to support research activity, however, ${ }^{56}$ all cite the important role of oneto-one guidance within the spread of support activities offered. A previous paper ${ }^{6}$ described the nature of the help that practitioners wanted when expressing interest in research and concluded that although the intention was to support research activity the nature of the advisory work was often a form of educational guidance and/or professional development counselling with practitioners asking for help as they make choices about involvement in research activities and research training and as they learn how to undertake research projects. This paper considers some of the emerging ethical issues involved in providing this sort of guidance in support of practitioner research activity.

In offering one-to-one guidance an advisory service is recognising the need to move beyond a position where the request for help involves providing a straightforward factual response to a straightforward factual query. Instead the adviser takes some responsibility for helping to unravel the issues involved in the request for help and in negotiating a passage through further activities. In doing so the adviser necessarily draws on many of the skills associated with educational guidance. ${ }^{6}$ It is thus inevitable that, as the advisers work closely with individual practitioners, the role of some of them will develop further, towards a relationship of professional development counselling. ${ }^{6}$ This paper reviews the practice of one-to-one guidance in support of research activities in the light of the principles of good practice which have been established for educational guidance and counselling within kindred disciplines.

The author draws on this literature and on her experience as an adviser who has provided individual guidance to over 80 primary care practitioners expressing interest in research, over a five year period. ${ }^{6}$

Various relevant codes/principles of good practice exist. The National Advisory Council for Careers and Educational Guidance (NACCEG) has produced a comprehensive document on "quality standards". ${ }^{7}$ These standards are founded in the earlier work on guidance principles by Hawthorn ${ }^{8}$ and adopt a client-focused ethos. In defining standards the guidance council recognises that guidance services may be provided within organisations not primarily established for this purpose and the requirements of such a scenario are specifically addressed. Other principles and standards of relevance are: "Principles for guidance and learner support", which was provided as part of a quality assurance framework recommended by the Higher Education Quality Council (HEQC) and the "Code of ethics and practice for counsellors" from the British Association for Counsellors (BAC). ${ }^{10}$

These codes and principles cover a broad range of guidance and counselling activities. No single code would appear to have direct and unequivocal relevance to one-to-one guidance as offered in connection with research support but they do provide an established professional foundation against which to review our own principles and practices.

Within the literature on research support initiatives which already exist we begin to see the emergence of various ethical dilemmas. Leighton-Beck ${ }^{5}$ raises concerns about attribution of success. Evans, ${ }^{1}$ reporting detailed case studies of 19 research support initiatives, describes the dilemmas experienced in allocating help (should help be concentrated on those most capable of undertaking successful research or equally available to all) and in the use of databases about clients/inquirers (should data be made available to other interest groups). Rest ${ }^{11}$ observes that ethical sensitivity is a necessary first step towards ethical practice, and Carroll ${ }^{12}$ reminds us that resolving ethical dilemmas via intuition is unlikely to be adequate; rather, we should use codes of practice, case examples, and discussion within the particular individual and organisational contexts in order to inform our understanding and response. Our ultimate aim should be to improve the ethical basis of our organisational practice. ${ }^{13}$

\section{THE RESEARCH ADVISER'S ROLE}

Responsibility for recognising and resolving ethical dilemmas on a day-to-day basis is likely to rest with those who assume roles as research advisers/coordinators. The requirements specified for this role and the settings within which the role may operate vary greatly. For example Evans ${ }^{1}$ found that advisers might be researchers, clinicians or neither; might operate under the management of an academic department or steering group or autonomously, or might be the recipient of small-scale funding (less than $£ 20,000$ per year) or major 
funding (more than $£ 200,000$ per year). Despite the apparent disparity of provision, 15 of the 19 initiatives surveyed saw the provision of support to practitioners on a one-to-one basis as their predominant activity.

Funding for research support initiatives tends to be short term. Continued funding for each initiative and therefore for the research adviser's/coordinator's post is likely to be dependent on the ability of the research adviser/coordinator to demonstrate satisfactory "results" or outcomes within a limited time-frame. The essence of the situation is therefore that those who offer research support must be able to demonstrate the contribution of their efforts if the service is to continue. To achieve this they must have a clear view of the way in which value will be ascribed to their activities and a mechanism for recording what has been achieved. The way in which activities are: (1) defined in terms of objectives/ outcomes and (2) recorded and reported, particularly in the context of one-to-one guidance, provides the backdrop for many of the ethical issues currently confronting research support initiatives.

\section{ETHICAL ISSUES IN THE CONTEXT OF OBJECTIVES AND OUTCOMES}

Evans $^{1}$ reviewed the stated aims across a survey of 19 established research support initiatives. The three main aims he identified, all derived from national policy, were:

". . . promoting high quality research by primary care practitioners, promoting high quality collaborative projects among primary care practitioners and promoting research awareness among primary care practitioners".

None of these aims in any way directly prioritises the needs and values of the individual practitioner. The perception that one-to-one guidance might be adopted against an agenda which is working towards strategically, and not individually, defined goals raises an important ethical dilemma since as the HEQC principles state ${ }^{9}$ :

\section{"learners are entitled to support in making learning choices most appropriate to their own goals, require- ments, expectations, personal circumstances and achievements".}

and Hawthorn ${ }^{8}$ states that those offering guidance should:

\section{"give precedence to professional responsibilities over institutional pressures and personal interests whilst acknowledging their accountability to those under whose professional authority they work".}

To what extent might these principles have relevance to the role of individual research advisers? To what extent should those acting as advisers to individual practitioners give the impression of operating as an impartial advisory service and to what extent can they legitimately operate as instruments of change towards a predefined set of strategic aims (as itemised in the quote from Evans above)? Three commonly familiar examples show how readily subtle conflicts of interest may arise.

- Suppose a practitioner inquirer is interested in learning about research methods. Should the adviser attempt to understand the nature and level of this interest in order to guide the inquirer to the most suitable opportunity available, and should the adviser have access to the information resources to make this wider choice possible, or should the adviser automatically recommend attendance at a course run as part of the range of activities operated through the research support initiative or host organisation? The partiality which can arise through a bounded knowledge of opportunities available is a recognised issue within guidance services. ${ }^{14}$

- Suppose the practitioner inquirer is enthusiastic about pursuing some research-related activity but is clearly not well placed in terms of personal and professional circumstances at present. Should the adviser encourage the inquirer to "have a go" regardless of circumstance or should the adviser encourage the inquirer to reassess his or her aspirations and position even if this means involvement in research activities will be delayed, possibly indefinitely?

- Suppose the practitioner inquirer wishes to undertake a small research project in order to improve some aspect of his local practice. Should the adviser encourage the inquirer to aim for generalisability with a possible reduction in local specificity but a greater potential for future publication or should the adviser support the inquirer in an activity which may only have very local relevance?

In many such situations the adviser is inevitably in a situation of underlying tension whereby figures recorded about the activities of the research support initiative would benefit from one course of action and, arguably, the inquirer as an individual might achieve greatest benefit from another. It is likely that individual advisers and individual initiatives have their own approaches to the management of these particular dilemmas. This paper is arguing that as our approach to the provision of advice about research activity matures we may need to become more explicitly alert to the occurrence of such dilemmas and more prepared to justify our handling of such situations in terms of established and debated principles and practices.

While we may feel it is inappropriate to align the role of research advisers with those offering independent advice on educational guidance and personal development we should consider the expectations of the service held by those who seek help and the extent to which the partial nature of the advice on offer is understood. Our own research support initiative was originally so small that it offered no courses of its own nor was it linked to any particular research projects or developments. Somewhat to our surprise feedback within a postal evaluation suggested that some practitioners particularly valued what they perceived to be the "independence" of the advice received. Further comments were made about practitioner centredness and the importance of the adviser responding to the situation as understood by the inquirer. These comments may indicate that the advice provided was perceived to serve the practitioner's own individual best interests rather than some underlying institutional outcomes and that this was both recognised and valued.

The experience of those working in more established guidance services suggests that clarity over policy is essential. ${ }^{7}$ Sources of funding will inevitably mean that various guidance and advisory services are working to agendas which will determine the context and boundaries of the advice that they offer. The standards recommended by $\mathrm{NACCEG}^{7}$ state that guidance services working in such contexts should provide a statement of policy which is clear about:

- what the guidance provider must achieve in order to secure its revenue under the contract

- the criteria against which the guidance provider will be measured

When we define our activities within a research support initiative we may need to analyse and explain more clearly what it is we are offering and what agenda we are servicing so that those who engage with the help and opportunities on offer can assess the quality and potential partiality of the guidance and services provided for themselves. 


\section{ETHICAL ISSUES IN THE CONTEXT OF THE CLIENT/INQUIRER RECORD}

Clearly it is important to maintain records about practitioner inquiries and inquirers. The record has formative value in enabling the research advisers to keep track of the unfolding needs and development of each individual inquirer while also enabling the adviser to build a constructive overview of the needs, priorities, and development across a group. ${ }^{6}$

However, the amount of information which should be recorded about each inquirer and the extent to which this information should be made available to others is less clear cut. The National Advisory Council for Careers and Educational Guidance ${ }^{7}$ and the BAC $^{10}$ both advise explicit discussion about issues of confidentiality and in particular, clarity about the use of the client record. The necessity to share basic details about client inquirers with those to whom the activity is accountable is, however, accepted.

In terms of the guidance offered in connection with research support we might envisage a package of information about any individual raising an inquiry which could include:
- name
- contact details
- technical nature of inquiry
- personal circumstances and support
- professional circumstances and support
- aspirations
- financial position and requirements
- named collaborators
- previous research interest/experience
- publications

Much of this information could have relevance in terms of a justification for the support/guidance service provided but equally much of this information could rightfully be regarded as confidential or at least "personally owned" by each individual concerned. The problem of sharing data for purposes of accountability may be aggravated within research support initiatives which are accountable to a management committee with a potentially changing membership. (Evans ${ }^{1}$ reported the existence of such management committees in 13 out of 19 networks reviewed). Explicit consideration may need to be given to the level of confidentiality which does or does not need to be preserved in this relatively uncontrolled setting and to the way in which recorded data is made available in order to account for resources used without unnecessarily exposing details which clearly relate to the confidential/ personally owned concerns of identifiable individuals.

Several research support initiatives offer advice to those individuals who are identified as "members". (Evans reported a membership system within eight out of 19 initiatives studied in 1997). Membership will usually require inquirers to offer details about themselves for inclusion on a database. It is likely that growing concerns over governance in relation to research funding will lead to an increase in the number of initiatives adopting a membership database. ${ }^{4}$ This database may be used to demonstrate the spread of practitioners to which the initiative has access or may be used more actively to follow up contacts to evaluate the impact of the advisory relationship or to send out mailshots or surveys from other interest groups. Clearly the use of such data must comply with the requirements of the Data Protection Act. Because membership is often offered without a fee, however, the appropriateness of the underlying obligations associated with membership may not yet have received sufficient scrutiny. The process of membership raises two particular ethical issues.

1. To what extent are the rights and responsibilities of "membership" made clear to individual practitioners?
2. To what extent is it appropriate to tie the offer of help to a commitment to untenured membership of the "helpproviding" organisation?

It is noted above that in order to maintain funding, research support initiatives must demonstrate "success". In order to demonstrate success an initiative based around the concept of "membership" can readily count: number of members; number of members attending meetings; number of practices represented through members, and number of presentations and publications by members. Individual members may feel that some of this information belongs to the individual and not to the initiative and this is already known to lead to tensions in the reporting of results. ${ }^{15}$ One solution may be to specify clearly the implications when an individual is assumed to have become a member. However, if we are moving to a position where we accept that there are obligations associated with membership then we must also move to a position where we accept that individuals may choose formally to relinquish membership. This is an interesting concept in terms of research support since initiatives want to demonstrate an ever-increasing "clientele" and it is not clear whether many yet entertain the concept of "relinquishing membership". In effect we are suggesting making the position more explicit when in exchange for help and support an initiative is claiming the right to record and cite the future activity and success of individual members. It may be that if made explicit and formalised in this way more practitioners would wish to question the appropriateness of the underlying "contractual" relationship and to refine its terms.

Whether or not a membership relationship is involved, it would seem desirable that the nature and uses of data held be made known to practitioner inquirers following initial contact, over and above the minimal requirements of the Data Protection Act. It is also incumbent upon the advisers or management steering group, however, to ensure that this relatively empowered position is not abused. Advisers working within research support initiatives may represent the only source of relevant advice to which the inquirer can turn. Increasingly there is a requirement for practitioners to refer to a named advisory source before submitting funding or accreditation applications. From this position it would be quite possible for advisers to set conditions about membership and/or about use of data with which inquirers feel uncomfortable but which they have little option but to accept.

The solution may be to involve inquirers, funders, and other stakeholders in the specification of a code of practice document which would include consideration of the rights and responsibilities of those offering help and of those seeking help (see box 1). This document should recognise that some inquirers who have a genuine need for help also have a genuine need to retain responsibility for their ideas and their progress. Any decision to reduce the availability of expert help to such individuals because they wish to retain individual autonomy over their own projects and commitments should be carefully considered and justified.

Through the application of the "code of practice" we could develop documentation which defines a quasi-contractual relationship between the guidance service and the practitioner community. At the level of overall service provision this could draw directly from the rights and responsibilities outlined through realisation of the code of practice (item 3). At the level of the individual practitioner this could become a more detailed document describing the nature and extent of the guidance relationship which had been negotiated to suit that particular need and set of circumstances (see box 2).

Clearly this level of detail would only be appropriate where the one-to-one relationship was likely to be of a longer term nature with more than a superficial "investment" of time and commitment from both parties. The provision and explicit documentation of individually tailored support activities is closely in accordance with current practice as implemented by 
Box 1 "Code of practice"-elements for consideration

Services funded to offer one-to-one guidance about research:

1. Should make the following information available to those seeking help:

- The underlying objectives of the service as determined by the funders

- The criteria by which the provision and impact of the services offered will be measured

2. Should define and make readily available an explicit policy to cover:

- The nature and limits of confidentiality over the handling of information about individuals and their concerns

- The nature and limits of eligibility over who is entitled to ask for help and in what circumstances

3. Should negotiate an agreed position over the rights and responsibilities of those who fund help, those who provide help and those who seek help

4. Should ensure that those seeking help are aware of the rights and responsibilities associated with the acceptance of help from the service

5. Should seek out and monitor concerns about policies defined in 1-4 and about the working of the guidance service in general

Box 2 Quasi-contractual relationship between the individual seeking help and the individual adviser

The adviser and the individual seeking help should agree and document:

1. The desired end point or outcome of the relationship

2. The nature and extent of the help to be provided by the adviser (and/or advisory service)

3. The nature and extent of the activity to be undertaken by the individual seeking help

4. Any specific obligations the service might expect of the individual as a consequence of receiving help

other established guidance and counselling agencies. ${ }^{7}{ }^{10}$ It has the advantage of clarifying the nature of the relationship at the outset such that the intended outcomes, timescale and resource commitment are agreed and available for future reference.

\section{CONCLUSION}

The discussion above has concentrated on the way in which value is ascribed to guidance activities and the way in which such activities are recorded and reported. The necessity for funded advisory services to demonstrate satisfactory performance has brought these issues into current focus and has determined the way in which we frame this particular ethical debate. ${ }^{15}$ However, many closely associated issues about the nature of a guidance relationship, the expectations held by those contributing to the relationship and the use and ownership of any outputs from the relationship also have relevance in other settings involving the supervision of research activity.

Further progress will need to recognise the importance of involving those who fund help, those who provide help and those who seek help in determining what constitutes ethical practice. The discussion within this paper has highlighted, in particular, the importance of the concept of client autonomy- the right of the client (practitioner) to be made aware of the limits of impartiality within the service with which he/she has made contact and the right of the client (practitioner) to retain ownership over his/her own information and the use to which this is put. Both of these rights, if accommodated, may weaken the position of the initiative to direct its activities to predetermined institutional goals and to account for that direction using the records and achievements of individual inquirers. The position of the initiatives may be strengthened, however, through demonstrable alignment with established guidance services and standards and through the adoption of associated quality assurance and monitoring processes which already exist in these fields.

\section{ACKNOWLEDGEMENTS}

The author would like to thank Professor Ann Louise Kinmonth and Dorothy Robbie, both of whom have contributed to the evolution of the ideas discussed and to the content of this paper. The author would also like to thank the many practitioners with whom she has worked, especially those who have been prepared to voice concerns and criticisms which have helped to shape her awareness of the ethical issues involved.

The author was in receipt of funding from NHS R\&D Eastern Region and gratefully acknowledges the support of Regional R\&D officers.

\section{Author's affiliations}

H Bateman, General Practice and Primary Care Research Unit, Cambridge University, University Forvie Site, Robinson Way, Cambridge CB2 2SR, UK

\section{REFERENCES}

1 Evans D, Exworthy M, Pekham S, et al. Primary care networks. Report to the NHS Executive South \& West R\&D Directorate. Southampton: Institute for Health Policy Studies, University of Southampton, 1997.

2 NHS Executive South \& West National Working Group on R\&D in Primary Care. Final report. Bristol: NHS Executive South and West, Research and Development Directorate, 1997

3 Medical Research Council. MRC topic review: primary health care. London: Medical Research Council, 1997.

4 Department of Health. Research and development for a first class service: R\&D funding in the new NHS. Leeds: The Stationery Office, 2000.

5 Leighton-Beck L. Increasing research capability: the tasks, development and output of a local research network. Health Bulletin 1998; 56:905-18.

6 Bateman H, Kinmonth A-L. Journeys and pathways: exploring the role of professional development advice and educational guidance for practitioners expressing interest in research. Medical Education 2001:35:49-55.

7 National Advisory Council for Careers and Educational Guidance. Quality standards. Winchester: NACCEG, 2000. Available at http://www.guidancecouncil.com [accessed September 19, 2000].

8 Hawthorn R. First steps: a quality standards framework for guidance across all sectors. London: RSA, 1995.

9 Higher Education Quality Council. A Quality assurance framework for guidance and learner support in higher education: the guidelines. London: HEQC, 1995

10 British Association for Counselling. Code of ethics and practice for counsellors. Rugby: BAC, 1998. Available at http://www.bac.co.uk [accessed September 19, 2000].

11 Rest J. Research on moral development:implications for training counselling psychologists. The Counseling Psychologist 1984;12:19-29.

12 Carroll M. Workplace counselling. London: Sage, 1996.

13 Blake DC. Organizational ethics: creating structural and cultural change in healthcare organizations. The Journal of Clinical Ethics 1999; 10: 187-93.

14 Connelly G. Impartiality in adult guidance: a Scottish study. In: Crawford M, Richards E, Kydd L, eds. Taking issue. London: Routledge, 1998.

15 McCrickerd J. Metaphors, models and organisational ethics in health care. Journal of Medical Ethics 2000;26:340-5. 